\title{
GENERATING ALTERNATIVE PROPOSALS FOR THE LOUVRE USING PROCEDURAL MODELING
}

\author{
Erica Calogero ${ }^{1}$ and David Arnold ${ }^{1}$ \\ ${ }^{1}$ University of Brighton, Moulescombe, Brighton BN2 4GJ, U.K., \\ http://www.culturalinformatics.org.uk, E.Calogero@brighton.ac.uk, D.Arnold@brighton.ac.uk
}

KEY WORDS: procedural modelling, reconstruction, case study, Louvre, architecture

\begin{abstract}
:
This paper presents the process of reconstructing two facade designs for the East wing of the Louvre using procedural modeling. The first proposal reconstructed is Louis Le Vau's 1662 scheme and the second is the 1668 design of the "petit conseil" that still stands today. The initial results presented show how such reconstructions may aid general and expert understanding of the two designs. It is claimed that by formalizing the facade description into a shape grammar in CityEngine, a systematized approach to a stylistic analysis is possible. It is also asserted that such an analysis is still best understood in the historical context of what is known about the contemporary design intentions of the building creators and commissioners.
\end{abstract}

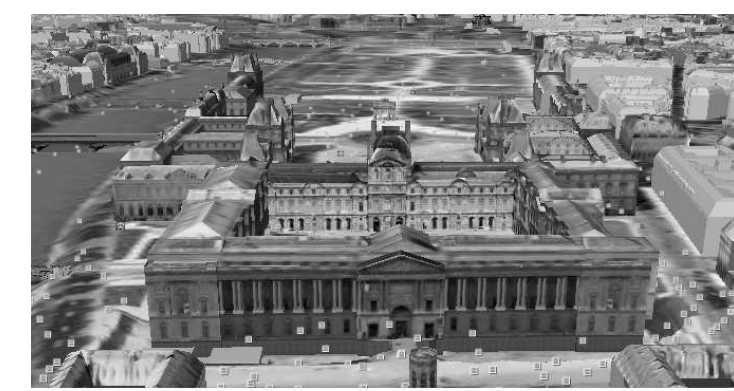

Figure 1: Aerial Photograph of the Louvre showing the Main facade of the East Wing of the Cour Carre courtesy of Google Earth

\section{INTRODUCTION}

This paper presents work done to create two 3D digital reconstructions of the east wing of the Louvre, one as it might have been built before the "Colbert Consultation" that took place between 1664 and 1672, and another the "as-built" structure of the final design as it stands today. The ultimate purpose of doing so is to allow the general public and expert users alike to explore and examine, in a 3D virtual environment, what the Louvre palace might have looked like had the earlier proposal been built. Furthermore, it will allow both categories to make analytic and stylistic comparisons. The work presented is part of an ongoing project to document the evolution of designs and stylistic choices for the east wing of the Louvre in a systematic 3D representation that allows for formal analysis. Procedural rules have been formulated to generate the facades of the proposals, given building plans and elevations taken from the archives of the Louvre. The rules were written as .cga files in the CityEngine software package.

\section{BACKGROUND}

\subsection{Related Work}

This work builds on recent interest in the use of procedural modeling to set up shape grammars that encapsulate architectural style within and for the use of the Cultural Heritage sector. In particular samples from ancient Rome, Pompei and Maya have been defined (Mueller et al., 2006), (Dylla et al., 2009), (Maim et al., 2007), often with stochastic parameters in their definition that allow for plausible yet pleasingly random variations. However, this recent flurry of interest within the computer science community in the encapsulating of building type and style into formalized rules is merely an application of the latest technology and computer science processes to an enterprise that stretches back for several centuries at least. One could argue that it started with the architectural treatise of Vitruvius (Vitruvius, 1960), lay dormant for several centuries, and was taken up in the rennaissance by authors such as Serlio (Serlio, 1982), Francesco di Giorgio (di Giorgio Martini, 1841) and Palladio (Palladio, 2002).

In the last century, although the heuristics presented in the ancient treatises, texts and pattern books cited above were not exactly rewritten in the language of the day, efforts to encapsulate the hidden rules embodied in designs have been attempted by researchers extending Stiny's original formulation of shape grammars (Stiny and Mitchell, 1978). In addition to this early work on shape grammars, quantitative geographers, grounded in the work of von Thunen (Thunen, 1966), have attempted to lay the foundation for generative rules at the settlement scale while Christopher Alexander's group at Berkeley (Alexander et al., 1977) have attempted the same in the realm of architecture. Hillier and Hansen's theories of space syntax (Hillier and Hanson, 1984), on the other hand, start with a very clear conception of how rulesets restrict the generation of form, both in building and urban-scale artefacts whose starting point departs radically from the other traditions mentioned. This is not intended as an exhaustive literature review and there are many other figures in the arc of architectural theory than either attempt to set up or to uncover what Hersey terms "paradigmatic design" (Hersey and Freedman, 1992). In his words, paradigmatic design "generates buildings according to rules expressed by a model in the same way a large number of Latin verbs obey the paradigm amo, amas, amat".

Hillier and Hansen's work is particularly relevant and its impact overlooked in this latest effort at redefining the formalization process, as their work explores the result of less ordered, bottom-up processes of form generation, through the experimental testing of possible restrictions on an otherwise random process. Their analyses of settlement and habitation topology highlights the potential for a scale to exist between order and randomness. In their view, 
this can be expressed in terms of the number of rules required to generate a form. They use the labels long model to categorize forms which require a large number of rules in order to replicate their meaning, and short model to describe those which require few rules in order to do so.

Shape grammars take a top-down hierarchichal approach to defining the spatial arrangement, dimension, positioning, scale, symmetry of the facades or plans of buildings to which they have been adapted. The process can be descriped as a waterfall, from a unity into a set of nested multiples, all connected by the next level up in the generation process. This absolute hierarchy is certainly better suited to generating some styles and shapes than others. Luckily for us, it is well suited to defining the "paradigmatic styles" of the Western classical building tradition. This paper then adds to the shape grammar body of knowledge of building styles by contributing two new exemplars in this Western classical tradition. Furthermore it highlights casual, experiential insights that can be drawn from the resulting formalized structure that may, in future work, be sytematized into more powerful generalizations.

\subsection{Historical Context}

Between 1664 and 1672 Colbert, "Surintendent des Batiments du Roi" for Louis XIV, was charged with commissioning the extension of the Louvre to include a new East wing that would enclose three pre-existing sides of the "cour carre" and function as the main entrance. According to Berger (Berger, 1993), the masterplan for this new, classically styled Louvre and parts of the courtyard building had been in place for several centuries. Louis Le Vau, "premier architecte", produced an initial proposal, the foundations of which had already been built when Colbert expressed dissatisfaction with the scheme and announced a competition. Louis XIV, the "Roi Solieil" was young and ambitious and the project formed part of his court's plans to cement his power and to glorify his divine right of Kings and it was essential that this building project reflected these aims. The original designs were put on public display in Paris and French architects were invited to submit alternative plans. In his quest for the best solution, however, Colbert sent his representatives to Italy to solicit the designs of the leading architects of that country. First on his list, Bernini produced three schemes, the first of which includes sweeping Baroque undulations. Further proposals were sought by other Italian architects, including Carlo Rainaldi and Pietro da Cortona. For reasons of either national pride or stylistic exigence discussed later (c.f. section 4.1), the final design, by a "petit conseil", offered a departure from the line of thinking passed on from earlier schemes. It was seen as a new French style of architecture, based on new scholarship of the ancients that was the only style magnificent enough for this young prodigy of a King, whose iconography and symbolism was reinforced by the symbolic nature of its design.

As most of the archives of the competition were lost during the great fire of 1871, the drawings that remain represent at best incomplete fragments of schemes proposed by the different contenders to the title of architect of the Louvre. Using procedural tools has the potential for the systematic encoding of the facades whose elevations have been preserved; and for them to be applied to facades whose elevations have been lost. This work will inform a complete $3 \mathrm{D}$ reconstruction, which for the reasons given above may interest both the cultural heritage expert and the general public. It also may facilitate the understanding of how realistically achievable some of the more speculative designs may have been to construct.

The first design reconstructed and presented here is the 1663 design of Le Vau. The available source material that was used for the reconstruction was limited to an original scaled ground floor plan and a lengthwise section through the wing (figures 2 and 4). Furthermore, a 2D scaled elevation and 3D perspective sketch were used (figures $3 \& 4$ ). These later images were produced as reconstructions by Jean Trouvelot in the 1960's, who excavated and surveyed the remains of the foundations when reinstating the moat to the east. They therefore already embody some educated guesswork as to what the principal facade design might have looked like.

The second design we have reconstructed is the final design selected for construction (see figure 1). It was officially tasked to a committee ("petit conseil") consisting of Louis Le Vau, Charles Le Brun - "premier peintre" and member of the committee in charge of developing the King's iconography - and Claude Perrault - a physician, scientist, fledgling architect and architectural theorist who was in the process of publishing a French translation of Vitruvius. The basic form of this design had been finalized by 1668. The material used for the $3 \mathrm{D}$ reconstruction includes $2 \mathrm{D}$ digital survey plans of the Louvre as it stands today and a scale section by Trouvelot in the 60's (parts of which are used to make figure 5). These scale drawings were supplemented with dimensions and photographs taken on site by the authors.

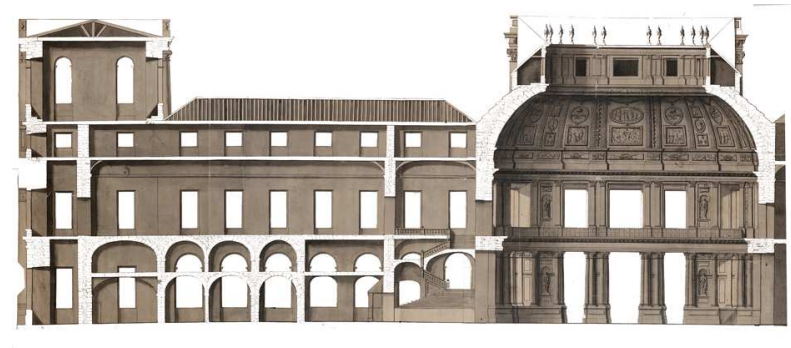

Figure 2: Le Vau's Original Long Section through the East Wing

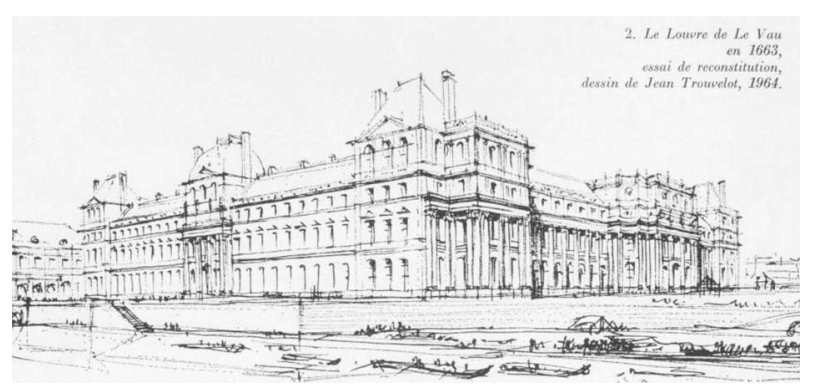

Figure 3: Trouvelot's Sketch Reconstruction of Le Vau's 1663 Design

\section{METHODOLOGY}

The process of reconstructing shape grammar hypotheses for the facades of the two projects presented above involved taking the available source material and tracing an initial outline of the building footprint from the available plans. In the case of Le Vau, where there are much more distinct building volumes, it also required a human interpretation of the plan and section information to produce component polygons of the plan that would correspond, when extruded, to the volumetric massing of the final shape. Although there is a computer algorithm that can automatically divide a complex polygon into simpler ones, it is a problem much beter suited to the human brain. There may however be scope for innovation in computer algorithms here.

The next step involved exporting the footprints as polygons in the .obj format into CityEngine, extruding the shapes and creating a 


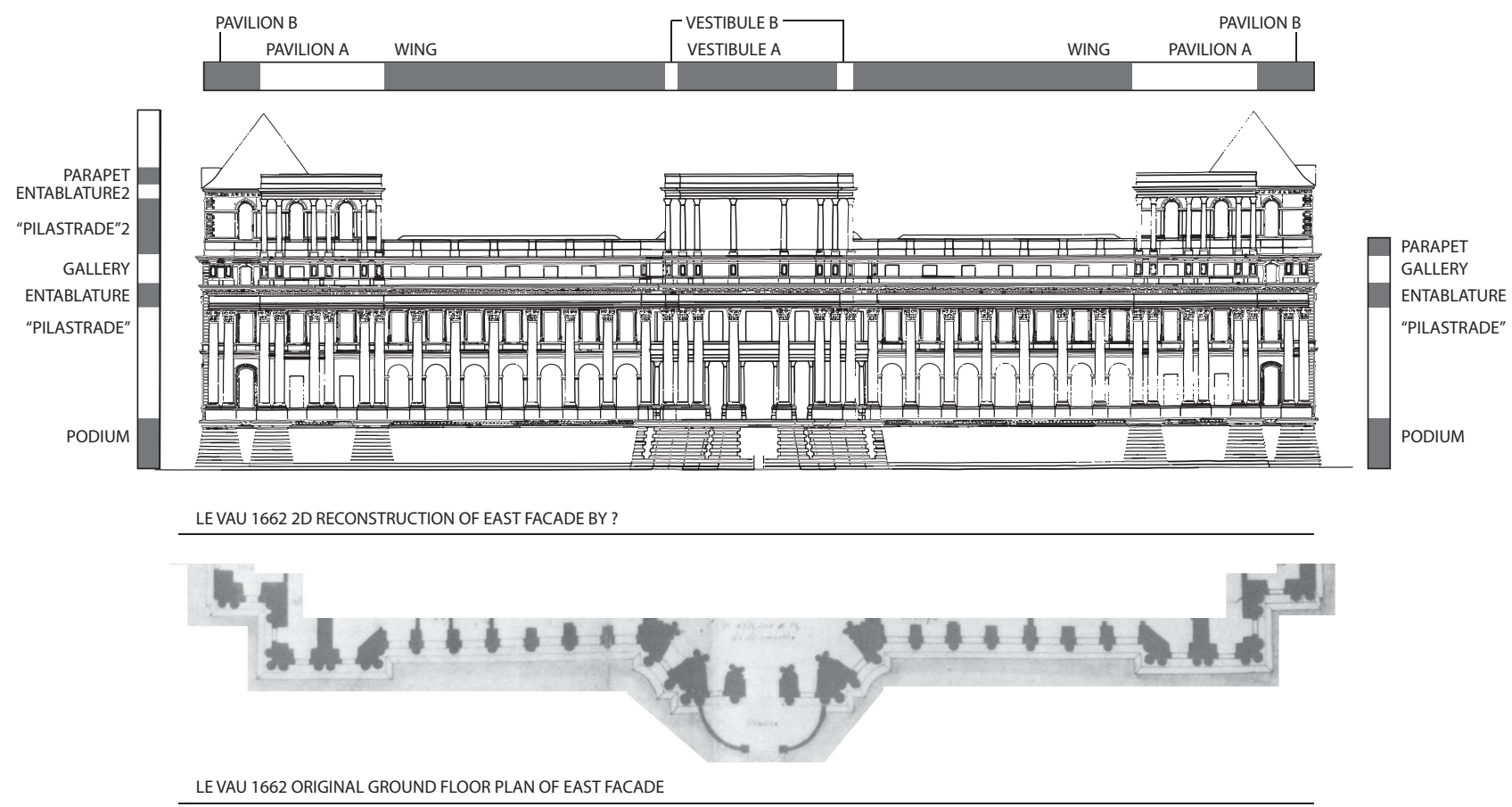

Figure 4: Diagram of Splits for the Le Vau Design of 1662

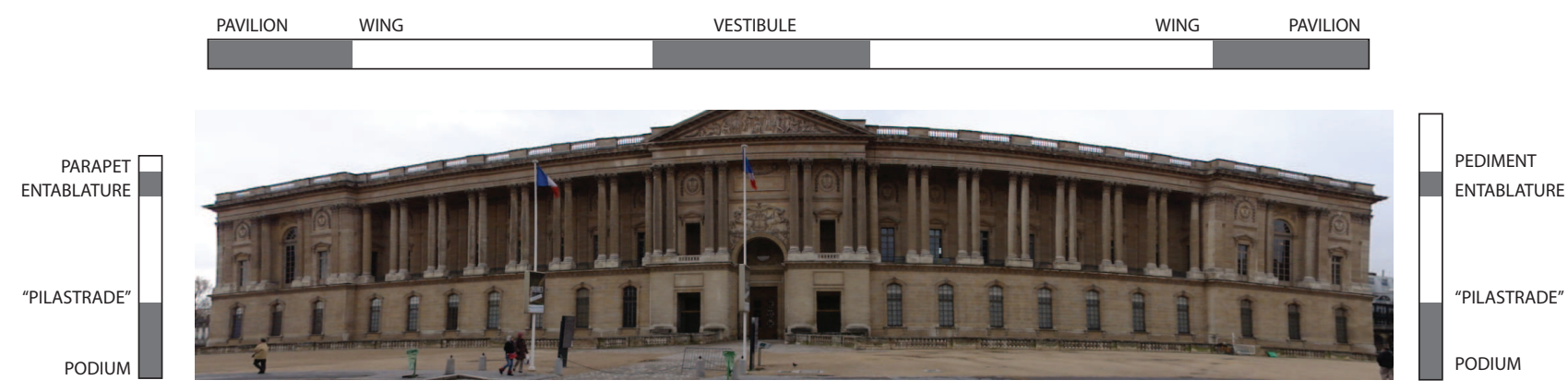

LE VAU/PERRAULT/LE BRUN 1664 PHOTOGRAPH OF AS BUILT DESIGN

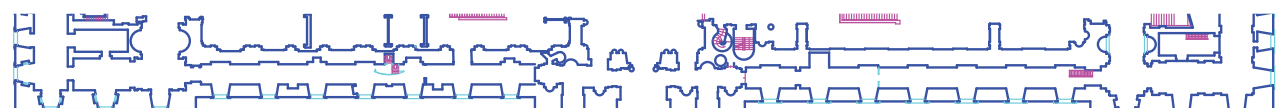

LE VAU/PERRAULT/LE BRUN 1664 GROUND FLOOR SURVEY PLAN OF EAST FACADE

Figure 5: Diagram of Splits for the Le Vau/Perrault/Le Brun Design of 1668 
hierarchy of splits, insertions and transformations to reflect the information available about the facades. Figures 4 and 5 show the first two splits in bars along the top and sides of the elevations. Figure 6 then shows examples how further splits are nested into the first split. It is important to know that not only proportional but absolute dimensions were specified, given the availability of this information from the base material. However, where there was no measured, drawn, or photographed material, especially in the Le Vau reconstruction, some best guesses had to be made, and notes were incorporated into the grammar file to record where these were made.

As with the case of subdividing plans into polygons, there is no guarantee that another author (or computer algorithm) would have created the identical same hierarchichal splits to define the geometrical and shape divisions of the facades. There may be scope for further experimentation on this aspect to test the stability of the method given different operators or even to find computer automations. However, the ordering that was most obvious to the authors were chosen so that entities that look indivisible as a unity were not split into geometrically smaller pieces where possible. It is worth noting here that while items such as columns and entablatures are easy to individuate and preserve without breaking up other geometries, the first casualty of the split grammar approach in this sense are walls, which are invariably divided into meaningless terminal nodes, especially when a window is required to be inserted into them. A wall is a single semantic entity, as is a window, but while the grammar preserves the single semantic entityness of windows, it is not so kind to walls. Finally complicated geometries such as capitals were hand modelled and imported into terminal nodes in the grammar.

\section{RESULTS}

\section{1 “PETIT CONSEIL” Reconstruction}

The encapsulation of the contemporary construction of the east wing of the Louvre into a shape-grammar highlight in a quantitative fashion some of the explicit aims of the design as conceived by the "petit conseil" and their employer. The block has been modeled using one single 19-sided polygon of which 5 edges constitute the external facade; 3 the internal facade; 2 the north and south facades of the end pavilions; and the remainder, the rather inconsequential $1.8 \mathrm{~m}$ returns that modulate the massing of the volume into 3 pavilions connected by two wings. There is a single, vertical axis of bilateral and reflective symmetry on the building, and in addition there is a translatory symmetry in both the two end pavilions and the two connecting colonnaded wings. This means that it was only necessary to write 3 different facade rules to cover the representation of the front facade.

The overall ordering of the grammar is simplified into predominantly tripartite splits. The primary split is into pavilions and wings as mentioned above. The secondary split is a global decorative ordering scheme that evokes the tripartite horizontal structure of a classical temple and separates the volume into a pedestal base (ground floor and basement); a colonnade of colossal columns (first and second floors); and finally a trabeated entablature supporting either a balustrade or a pediment, which hides the pitched roofing of the building.

Both the overall building volume proportions and this simplified tripartite schema emphasizes both a horizontality and a unity of concept that allows the design to attain the characteristics of an ancient Greek or Roman temple, to a degree never before witnessed even after centuries of efforts from Filarete to Palladio and beyond. The functions of such ancient buildings were chiefly symbolic and ceremonial, devoted to the divine. The facade consciously reflected the latest scholarship on antiquity and the visual symbolism that it utilized invoked the mythic power and magnificence of the ancient deities. This was no accident, the building was considered a great success as it achieved its aim of elevating the residence of the Sun King to the same divine status of that of the ancient God of Apollo, the Sun God, rather than the residence of a mere mortal. It was this visual allegory of Apollo that formed the basis of much of the visual iconography developed for Louis by Le Brun and others. Figure 7 shows this reconstruction in the context of the same aerial photo in figure 1 for easy comparison with the original.

\section{2 "LE VAU" Reconstruction}

Le Vau's design was produced procedurally by subdividing the plan into 7 different polygons as a starting point to generate the volumetric massing and subsequently form the split grammar rules for the facades of the wing. All of these starting plan-polygons were rectangles except for the central pavilion containing the "salon a l'italienne". There is a single, vertical axis of bilateral and reflective symmetry, however there is no translatory symmetry in the end pavilion grammars, as they are not interchangeable. It was necessary to generate a total of 6 different facade rule files for the 11 faces of the front facade in order to encapsulate the geometry in a formal manner. It is therefore a marginally more complex building to encode into a split grammar hierarchy than the final built example (which had 3 rule files for 5 faces). Figure 8 shows this reconstruction in context for easy comparison with the reconstruction in figure 7 .

In addition to an increase in the length of the ruleset required to define the geometry, the overall ordering principle of the building is less simple and iconic. The primary split is also read as a central pavilion with two flanking towers, connected by two side wings. However, the flanking towers are modulated into a background tower and a foreground double portico on each side, and the central pavilion takes on Le Pautre's drum-without-dome motif (Berger, 1966), which Trouvelot's drawings suggest would be decorated with two sets of engaged colonnades as well. Even though the number of .cga rules needed is longer, if we were to conceive of this building facade in terms of Hillier and Hanson's long model short model categorization schema, the authors suspect that the conceptual rules required to generate (rather than merely describe) the volume would probably be fewer than those that would dictate the generation of the "petit conseil" design as defined above. There is therefore also scope for a deeper, more systematic analysis to test this conjecture.

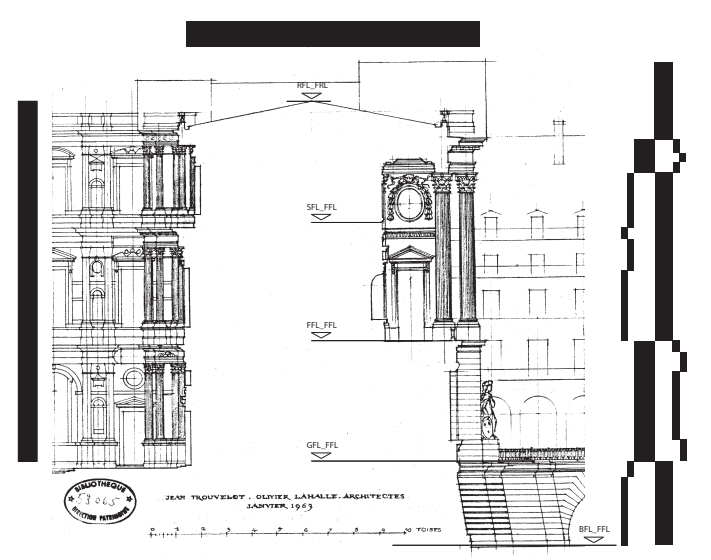

Figure 6: Trouvelot's Section Through the Existing East Wing Annotated with the Horizontal Split Ratios 


\section{DISCUSSION}

Creating a shape grammar hypothesis for the above described two designs for the front elevation of the east wing of the Louvre has permitted us to see how simplicity and symmetry can be reflected in the written rules that formally describe their shape and arrangement. It is seen how such measurable devices were used as allegorical devices to recall more ancient, religious structures, some of which have also been previously modelled in CityEngine. Such techniques have proven useful in therefore allowing a more precise analysis of the formal elements of the two facades. However, we have not addressed the issue of building typology, which is less well represented by shape grammar techniques, and better suited to other methods such as space-syntax type representations of both plan and elevation. It is proposed that such an analysis, and the synthesis of the two different types of representation would be the future steps to present a more complete and holistic formal analysis of shape, order and structure of this period of classical western architecture.

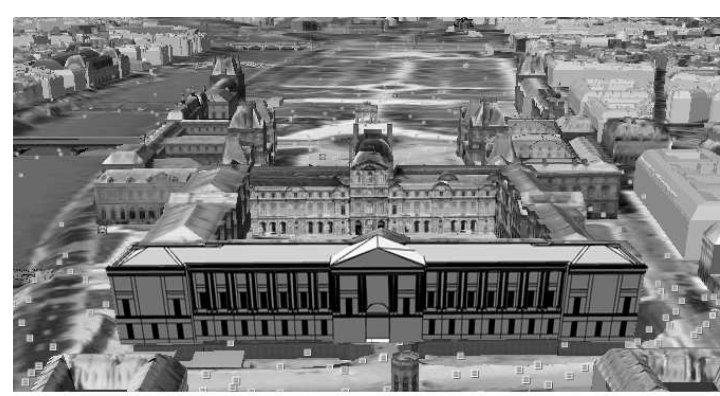

Figure 7: Reconstruction of the "petit conseil's final design for the East Wing of the Louvre, in the Context of a Google Earth Aerial photo

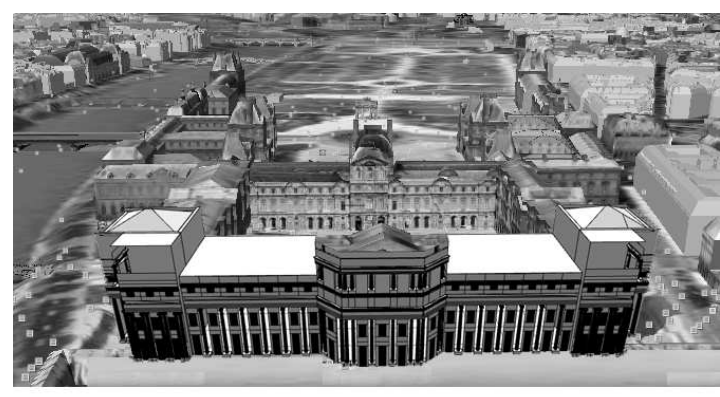

Figure 8: Reconstruction of Le Vau's 1663 design for the East Wing of the Louvre, in the Context of a Google Earth Aerial photo

\section{CONCLUSION}

This experiment represents an advance in the body of knowledge on the representation of classical building facades using the split grammar/ subdivision surfaces paradigm. CityEngine has been used to create speculative reconstructions of un-built scheme designs in cases where incomplete source information is available. Rather than populate an entire city with speculative facades; proportions, ornamentation and arrangements have been gleaned from historic archive material, and then used to fill in the hypothesis of missing elevations. Work with the rules is ongoing, and when complete will provide fresh insights into the architectural history of the development of the Louvre and contribute to a deeper understanding of contemporary national design styles in France and Italy in the 17th century. It will also allow for further representations to be made to the public, in the form of 3D, digitally printed models; a multimedia presentation of the information; and a virtual exhibit that can be accessed online.

\section{ACKNOWLEDGEMENTS}

This research was funded by EU Project 3D-COFORM. Thanks to M Guillaume Fonkenell and to the Louvre for facilitating access to the archives used and providing vital insights into the period of history and architectural style examined.

\section{REFERENCES}

Alexander, C., Ishikawa, S., Silverstein, M., i Rami, J. R., Jacobson, M. and Fiksdahl-King, I., 1977. A pattern language. Oxford Univ. Pr.

Berger, 1966. Antoine le pautre and the motif of the drumwithout-dome. The Journal of the Society of Architectural Historians 25 , pp. 165180 .

Berger, R., 1993. The Palace of the Sun: The Louvre of Louis XiV. Pennsylvania State University Press.

di Giorgio Martini, F., 1841. Trattato di architettura civile e militare. Tipografa Chirio e Mina.

Dylla, K. A., Mueller, P., Ulmer, A., Haegler, S. and Frischer, B. D., 2009. Rome reborn 2.0: a framework for virtual city reconstruction using procedural modeling techniques. In: Proceedings of the 37th Annual Conference, Envisioning the Past: Virtual Reconstructions of Archaeological Sites (CAA'09).

Hersey, G. L. and Freedman, R., 1992. Possible Palladian Villas: (plus a Few Instructively Impossible Ones). MIT Press, Cambridge, Mass.

Hillier, B. and Hanson, J., 1984. The social logic of space. Cambridge University Press Cambridge.

Maim, J., Haegler, S., Yersin, B., Mueller, P., Thalmann, D. and Gool, L. V., 2007. Populating ancient pompeii with crowds of virtual romans. In: 8th International Symposium on Virtual Reality, Archeology and Cultural Heritage-VAST.

Mueller, P., Vereenooghe, T., Wonka, P., Paap, I. and Gool, L. V., 2006. Procedural 3D reconstruction of puuc buildings in xkipche. In: Eurographics Symposium on Virtual Reality, Archaeology and Cultural Heritage (VAST), p. 139146.

Palladio, A., 2002. The four books on architecture. The MIT Press.

Serlio, S., 1982. The five books of architecture. Dover Publications.

Stiny, G. and Mitchell, W. J., 1978. The palladian grammar. Environment and Planning B 5(1), pp. 518.

Thunen, J. H. V., 1966. Isolated state. Pergamon Press.

Vitruvius, 1960. The Ten Books on Architecture. Courier Dover Publications. 